\title{
Swiss ball training to improve trunk control and balance in spastic hemiplegic cerebral palsy
}

\section{*C. Elanchezhian ${ }^{1}$, P. SwarnaKumari ${ }^{2}$}

Sri Lanka Journal of Child Health, 2019; 48(4): 300-304

\begin{abstract}
Introduction: Trunk control is one of the impairments in spastic hemiplegics which affects the balance in cerebral palsy children. Trunk balance is a pre-requisite for upper limb function. By improving trunk control, the balance increases, helping the child to be functionally independent.
\end{abstract}

Objectives: To improve trunk control and balance in spastic hemiplegic cerebral palsy children by Swiss ball training.

Method: Thirty subjects were included in the study after obtaining informed consent from their parents and they were separated into two groups. One group was given conventional training and the other group was given Swiss ball training for 30 minutes, 4 times weekly for 6 weeks. Gross Motor Functional Measure (GMFM-88) scale was utilized for assessment of trunk balance and Paediatric Balance Scale (PBS) for assessment of functional balance. Paired t-test was used to analyse the effect of trunk control and balance functions

Results: The post-test mean values of all the variables of Swiss ball training group were significantly improved compared to those of the conventional group $(\mathrm{p}<0.005)$.

Conclusions: The study shows that Swiss ball training improves trunk control and balance in spastic hemiplegic cerebral palsy children.

DOI: http://dx.doi.org/10.4038/sljch.v48i4.8821

(Keywords: Cerebral palsy, spastic hemiplegic, Swiss ball, trunk control, balance)

${ }^{1}$ Research Scholar, ${ }^{2}$ Associate Professor, $P G \&$ Research Department of Rehabilitation Science, Holy Cross College, Tiruchirapalli, India *Correspondence: elanchezhianrehab@gmail.com

orcid.org/ 0000-0002-5408-4030

(Received on 13 December 2018: Accepted after revision on 18 January 2019)

The authors declare that there are no conflicts of interest

Personal funding was used for the project.

Open Access Article published under the Creative

Commons Attribution CC-BY (c) (P)

\section{Introduction}

Cerebral palsy (CP) is a disorder of movement and posture due to non-progressive impairment in the developing brain ${ }^{1}$. This is frequently associated with affected speech, vision, hearing, mental retardation and epilepsy ${ }^{2}$. It is the commonest cause of childhood disability and is seen in 2-2.5 out of 1,000 births $^{3}$. CP is a group of conditions primarily affecting motor function due to an insult to the developing brain ${ }^{4}$.

The topographic classification of CP is hemiplegia, diplegia, and quadriplegia. Another classification is based on motor function as pyramidal (spastic) and extrapyramidal (non-spastic including athetoid, ataxic, and dystonic) $)^{5}$.

Hemiplegia represents a distribution of involvement of one half of the body. The common problem in hemiplegic $\mathrm{CP}$ children is flexion in the affected upper limb and extension in the affected lower limb, the foot on affected limb being plantar flexed. The affected side of trunk is weakened by the activation of the unaffected trunk, so that the child transfers the body weight to the unaffected side which flexes the normal side making the circumductory gait pattern in the affected lower limb. The activity of the affected side upper limb that is impaired by the voluntary actions is restricted due to spasticity on the affected side $^{6}$.

Spasticity is characterized by muscles that are perceived as stiff in which velocity dependent resistance to passive movement produces increased muscle tone, selective control is limited producing abnormal and limited movement synergies, the active range of motion is limited by co-activation of muscular activity and the timing of muscle activation and postural responses is abnormal. Spastic CP is the commonest type ${ }^{7}$. Novel treatment regimens have been continuously introduced, and debates on the effects of interventions are ongoing ${ }^{8}$.

Equipment is used in therapeutic exercises for the $\mathrm{CP}$ child. The therapist may use equipment to place the child in a position to enhance movement, inhibit undesirable responses, introducing ability into the context of movement assisting the handling and movement of larger patients. Mats, benches, bolsters, tilt board and Swiss ball are used for adaptive equipment. Among these, Swiss ball is an 
effective and adaptive equipment to develop the trunk balance and postural stability.

Treatment available to treat trunk balance includes hippotherapy. The aim was to assess whether children with $\mathrm{CP}$ show normal equilibrium reactions while horseback riding ${ }^{9,10}$. The Swiss ball can screen and evaluate balance problems, as a child exercising whilst seated on a gymnastic ball will require vestibular and proprioceptive feedback to make the appropriate adaptive responses ${ }^{11}$. Some of the effects in Swiss ball training are teaching the patient to move aligned trunk forward and backward in space, detect weakness in the abdominal muscles, stretch the ventral chain of the trunk, train balance and equilibrium reactions, facilitate lateral flexors, strengthen the abdominal muscles, stabilize the trunk, evaluate trunk balance, facilitate trunk rotation and stabilize trunk extension. Most of the Swiss ball exercises for adults can be modified for children $^{12}$. Swiss ball can influence trunk muscle activity in the abdominals and external oblique muscles during prone bridge exercises ${ }^{13}$.

\section{Objectives}

To determine the improvement in trunk control and balance in spastic hemiplegic CP children by using Swiss ball training.

\section{Method}

Study setting: In a private paediatric therapy centre. Sample size: Thirty subjects who were referred to the physiotherapy department with a provisional diagnosis of spastic hemiplegic cerebral palsy were taken up for the study. Many clinical studies have at least "30" samples, to ensure that you have exact enough mean and deviation estimates. This number comes from considering the central limit theorem to approximate your experimental results distribution with a Gaussian, so that confidence intervals are easier to calculate.

Sampling method ${ }^{14}$ : Convenience sampling.

Inclusion criteria: Children (male and female) in age group 4 to 11 years, with left or right side spastic hemiplegia, with GMFM scale sitting balance score less than 20 , medically stable and able to understand commands.

Exclusion Criteria: Children with severe mental retardation, severe epilepsy, other associated neurological disorders, other type of cerebral palsy, attention deficit hyperactivity disorder and sensory issues.

Ethical clearance: Ethical clearance was obtained from the Ethical Research Committee, Holy Cross College (Autonomous), Tiruchirapalli, Tamil Nadu, India

Outcome measures: Gross Motor Functional Measure (GMFM) scale was used to measure the overall gross motor functional activities especially in lying to sitting, sitting to standing, standing to walking and quadruped position. In this study 88 version was used for assessment ${ }^{15}$. Paediatric balance scale (PBS) was used to assess the functional balance. This scale consists of 14 items maximum point is 56 and this scale is sensitive to assess the balance of the paediatric population ${ }^{16}$.

Procedure: Informed consent was obtained from the parents before study. Prior to treatment session, trunk balance was assessed using GMFM scale and PBS and the values were recorded as pre-test values. Children were assigned into two groups with 15 children in each group. One group underwent Swiss ball training programme and the other group underwent conventional physiotherapy. Both groups underwent the training programme 4 times per weeks with the treatment session of 30 minutes for 6 weeks duration ${ }^{17}$. After the intervention, the subjects were assessed again to evaluate the trunk balance using GMFM scale and PBS and the values were recorded as post-test values.

Swiss Ball Activity ${ }^{10,12,13}$

- Positioning the child to sit on the ball and roll the ball side to side. This helps to develop postural control in children.

- Position the child to sit on the ball and giving extension rotation and flexion rotation to the child. This will facilitate trunk rotation by which the upper body is towards the weight bearing hip and away from the weight bearing hip.

- Position the child to sit on the ball with the lower extremities in dissociated position. Move the ball forward and backward diagonally. This facilitates pelvic femoral rotation and controlled used of flexors and extensors across the body which leads to equilibrium control in the trunk and hips.

- Making the child to sit on the ball and work on rotation of the trunk with stable pelvis and hip. An activity on reaching in different direction allows the child to work the trunk and lateral weight shifting.

- Position the child supine on the ball with the feet to the floor. Hold through the lower abdominals to stabilize them on to the ball. Now facilitate through one arm and bring the child diagonally up to stance.

Conventional Treatment $t^{18,19,20}$

- Positioning the child in prone lying on the mat and facilitate to lift the upper trunk with both arms extended with maintenance of the symmetrical position and instruct the child to reach forward with the targeted toys.

- By positioning the child in long sitting on the balance board and propelled on both sides using the reaching activities and 
develop the balance reactions in the long sitting position.

- Making the child in prone lying on the bolster and reach the target toy with both hands in the extended position repetitions are increased for training the movement.

- Positioning the child on side lying on the affected side upward, reaching activities are activated to the affected side and this will elongate the affected side trunk.

- Positioning in quadruped position on the tilt board and the reaching activity is activated by using the unaffected arm first and followed by the affected arm.

- Positioning in sitting position on the bolster and shifts the weight lateral and posterior by reaching the target for both sides.

\section{Results}

Table 1 shows the mean age, male to female ratio and side affected of the children who participated in the study. Table 2 compares the GMFM scale and the PBS (pre-test and post-test)

Table 1: Descriptive data of the participants

\begin{tabular}{|l|c|c|}
\hline \multicolumn{1}{|c|}{ Variable } & Conventional group & Swiss ball group \\
\hline Mean age (years) & 8.8 & 8.9 \\
\hline Male : female & $7: 8$ & $9: 6$ \\
\hline Right : left & $5: 10$ & $7: 8$ \\
\hline
\end{tabular}

Table 2: Comparison of GMFM scale and PBS (Pre-test and Post-test)

\begin{tabular}{|c|c|c|c|c|c|}
\hline \multirow{5}{*}{ GMFM Scale } & Group & & Mean & Standard Deviation & T-value \\
\hline & \multirow[t]{2}{*}{ Swiss ball } & Pre - test & 19.20 & 0.86 & \multirow[t]{2}{*}{12.762} \\
\hline & & Post- test & 30.00 & 3.40 & \\
\hline & \multirow[t]{2}{*}{ Conventional } & Pre - test & 19.13 & 0.91 & \multirow[t]{2}{*}{8.919} \\
\hline & & Post- test & 22.47 & 1.24 & \\
\hline \multirow{4}{*}{ PBS } & \multirow[t]{2}{*}{ Swiss ball } & Pre - test & 29.13 & 4.35 & \multirow[t]{2}{*}{12.093} \\
\hline & & Post- test & 42.00 & 6.41 & \\
\hline & \multirow[t]{2}{*}{ Conventional } & Pre - test & 27.07 & 2.25 & \multirow[t]{2}{*}{11.046} \\
\hline & & Post- test & 30.93 & 2.31 & \\
\hline
\end{tabular}

GMFM: Gross Motor Functional Measure, PBS: Paediatric balance scale

In Table 2 it is observed that the mean values of the Swiss ball group are higher compared to conventional group in both GMFM scale and PBS.
Table 3 compares post-test values of GMFM scale and PBS. There is a statistically significant improvement in both groups $(\mathrm{p}<0.005)$.

Table 3: Comparison of post-test values (GMFM and PBS)

\begin{tabular}{|l|c|c|c|c|c|c|}
\hline \multirow{2}{*}{ Group } & \multicolumn{2}{|c|}{ Swiss ball } & \multicolumn{2}{c|}{ Conventional } & \multirow{2}{*}{ T-test } & \multirow{2}{*}{ P value } \\
\cline { 2 - 6 } & Mean & SD & Mean & SD & & \\
\hline GMFM Scale & 30.00 & 3.40 & 22.47 & 1.24 & 8.054 & 0.000 \\
\hline PBS & 42.00 & 6.41 & 30.93 & 2.31 & 6.286 & 0.000 \\
\hline
\end{tabular}

GMFM: Gross Motor Functional Measure, PBS: Paediatric balance scale

\section{Discussion}

The statistical analysis has proved that this study is statistically significant as the calculated $p$ value is less than 0.05 for both the GMFM and PBS score. This also shows that the post-test mean values are higher compared to the pre-test mean values. EunYoung Park, suggested that physiotherapy is an important component in the treatment of cerebral palsy. The objective of therapy is improving corrective and balance reactions thus improving functional activities by preventing abnormal muscle tone ${ }^{21}$.

Frequency of treatment for six weeks contributed to significant changes made in children following Swiss ball training. Selection of appropriate activities also helped to improve the functional goal for 6 weeks resulting in significant changes in trunk balance in spastic hemiplegic CP. Woollcott. $\mathrm{M}$ et al (2005) showed the effect of balance training on muscle activity used in recovery of stability in children with $\mathrm{CP}^{22}$. Burtner PA et al (2007) compared children with $\mathrm{CP}$ and typically developing children regarding their capacity to adapt to changing balance threats ${ }^{23}$.

Tilting reactions are not totally different from equilibrium reactions. They include the same mechanisms of control but now the surface is moving. The surface moves the centre of gravity over a new base. Activities done on the broad base require less muscle activation; whereas activities done with a small base will require more muscle activation when compared. As the base of support 
used in Swiss ball activities are very minimal the muscle activated greater than any other method.

\section{Conclusions}

This study shows that the Swiss ball is an effective tool for developing the trunk muscle activity, strengthen the core muscles of the trunk and maintain the stability in upright positions and it gives freedom to the upper limb activities. In Swiss ball, all types of weight shifting are activated with minimal transitions so that the energy expenditure of the therapist is less than the other adaptive aids. This approach is more significant than the conventional treatment approach.

\section{References}

1. Dekkers KJFM, Rameckers EAA, Smeets RJEM, Janssen-Potten YJM. Upper extremity strength measurement for children with cerebral palsy: A systematic review of available instruments. Physical Therapy 2014; 94(5): 609-22. https://doi.org/10.2522/ptj.20130166 PMid: 24415772

2. Ghai OP, Editor. Essential Pediatrics. Eight Edition. CBS Publishers page; 2013. p. 581-3.

3. Elanchezhian C, SwarnaKumari P. Physical rehabilitation techniques to improve hand function in cerebral palsy. Indian Journal of Applied Research 2017; 7(5): 377-9.

4. Parkes J, Hill N, Dolk H, Donnelly M. What influences physiotherapy use by children with cerebral palsy? Childcare, Health \& Development 2004; 30(2):15160.

https://doi.org/10.1111/j.13652214.2003.0 0399.x

PMid: 14961867

5. Shamsoddini A, Rasti Z, Kalantari M, Hollisaz MT, Sobhani V, Dalvand H, et al. The impact of Kinesio taping technique on children with cerebral palsy. Iranian Journal of Neurology 2016; 15(4): 219-27. PMid: 28435631 PMCid: PMC5392196

6. Van Roon D, Steenbergen B, Meulenbroek RG. Trunk use and co-contraction in cerebral palsy. Neuropsychologia 2005; 43(4):497-508.

https://doi.org/10.1016/j.neuropsychologia .2004.07.014

PMid: 15716140
7. Hypes B. Facilitating development and sensorimotor function - Treatment with the ball. Therapy Skill Builders; 1991.

8. Kim MJ. Cerebral palsy update - Focusing on the treatments and interventions. Hanyang Medical Reviews 2016; 36:59-64. https://doi.org/10.7599/hmr.2016.36.1.59

9. Elanchezhian C, SwarnaKumari P. Physiotherapy techniques to improve posture and balance in cerebral palsy- A review. North Asian International Research Journal of Social Science \& Humanities 2018; 4(4): 107-14.

10. Mac Phail HEA, Edwards J, Golding J, Miller K, Mosier C, Zwiers T. Trunk postural reactions in children with and without cerebral palsy during therapeutic horseback riding. Pediatric Physical Therapy 1998; 10(4):143-7.

11. Umphred DA, Lazaro R. Neurological Rehabilitation. 6th edition. Mosby; 2012.

12. Carriere B. The Swiss Ball. Theory, Basic Exercises and Clinical Application. 1st edition. Springer; 1998.

13. Lehman GJ, Hoda W, Oliver S. Trunk muscle activity during bridging exercises on and off a Swiss ball. Chiropractic and Osteopathy 2005; 13: 14.

https://doi.org/10.1186/1746-1340-13-14

PMid: 16053529 PMCid: PMC1187901

14. Campbell SK, Palisano RJ, Orlin M. Physical Therapy for Children, $4^{\text {th }}$ Edition. Elsevier, 2012.

15. Ko J, Kim MY. Reliability and responsiveness of the gross motor function measure-88 in children with cerebral palsy. Physical Therapy 2013; 93(3): 393-400. https://doi.org/10.2522/ptj.20110374 PMid: 23139425

16. Franjoine MR, Darr N, Held SL, Kott K, Young BL. The performance of children developing typically on the Pediatric Balance Scale. Pediatric Physical Therapy 2010; 22:350-9. https://doi.org/10.1097/PEP.0b013e3181f 9d5eb

PMid: 21068635

17. Dewari R, Love S, Johnston LM. Exercise interventions improve postural control in children with cerebral palsy: a systematic 
review. Developmental Medicine \& Child Neurology 2015; 57: 504-20.

https://doi.org/10.1111/dmcn. 12660

PMid: 25523410

18. El-Basatiny HMY, Abdel-aziem AA. Effect of trunk exercises on trunk control, balance and mobility function in children with hemiparetic cerebral palsy. International Journal of Therapies and Rehabilitation Research 2015; 4(5): 23643.

https://doi.org/10.5455/ijtrr.00000094

19. Bonnechère B, Omelina L, Jansen B, Van Sint Jan S. Balance improvement after physical therapy training using specially developed serious games for cerebral palsy children: preliminary results. Disability and Rehabilitation 2017; 39(4):403-6.

https://doi.org/10.3109/09638288.2015.10 73373

PMid: 28033958

20. Karabay İ, Dogan A, Arslan MD, Dost G, Ozgirgin N. Effects of functional electrical stimulation on trunk control in children with diplegic cerebral palsy. Disability and Rehabilitation 2012; 34(11):965-70. https://doi.org/10.3109/09638288.2011.62 8741

PMid: 22149464
21. Park E-Y, Kim W-H. Effect of neurodevelopmental treatment-based physical therapy on the change of muscle strength, spasticity, and gross motor function in children with spastic cerebral palsy. Journal of Physical Therapy Science 2017; 29(6): 966-9.

https://doi.org/10.1589/jpts.29.966

PMid: 28626301 PMCid: PMC5468216

22. Woollacott M, Shumway-Cook A, Hutchinson S, Ciol M, Price R, Kartin D. Effect of balance training on muscle activity used in recovery of stability in children with cerebral palsy: a pilot study. Developmental Medicine \& Child Neurology 2005; 47: 455-61. https://doi.org/10.1017/S00121622050008 85

23. Burtner PA, Woollacott MH, Craft GL, Roncesvalles MN. The capacity to adapt to changing balance threats: a comparison of children with cerebral palsy and typically developing children. Developmental Neurorehabilitation 2007; 10(3):249-60. https://doi.org/10.1080/175184207013030 66

PMid: 17564865 